\title{
AWARENESS AMONG ADULT FEMALES ABOUT THYROID DISORDER ATTENDING NEURO AND ALLIED CLINIC, BHAIRAHAWA, RUPANDEHI, NEPAL
}

Mahesh Raj Ghimire, ${ }^{1}$ Sulochana Ghimire Thapa, ${ }^{2}$ Lekhjung Thapa, ${ }^{3}$ Binita Soti ${ }^{4}$

\begin{abstract}
INTRODUCTION

Thyroid disorder is common endocrine disorder second to diabetes. With the advancement of laboratory facilities in urban and rural areas, detection rate of thyroid disorder is escalating. Both hyperthyroidism and hypothyroidism can lead to dreaded complication like hypertensive heart disease, coronary arterial disease, arthralgia, severe myalgia, infertility, arrhythmia and many more, so our study helps us to know the awareness amongst a group of population from mid Western part of Nepal.
\end{abstract}

\section{MATERIAL AND METHODS}

This is cross sectional descriptive study, conducted in mid Western region of Nepal, among 105 subjects attending Neuro and Allied Clinic, Bhairahawa, Nepal from 15 August, 2019 to 20 August. 2019.

\section{RESULTS}

Majority 42 (40\%) of participants are of age group 36-40 years and are housewives. All are literate and 91 (87\%) are married. Most of them 93 (88\%) know that it is common in female and one third of them has had their family history positive for this disorder. More than half 37 (53\%) of the respondents had inadequate awareness on thyroid disorders whereas 33 (47\%) had adequate awareness with mean score 19.9 and 12.4 standard deviation. The maximum score of awareness related question was 42 and minimum 3 obtained by the respondents out of 53. Finally, there is an association between age, education level, occupation status of respondents, respondent's family members or herself having thyroid disease with awareness level ( $\square \square 0.005)$, but no association between marital status and awareness level.

\section{CONCLUSION}

This study reveals majority of people are aware of thyroid disorder but still awareness is inadequate. So, it is mandatory to perform public awareness by NGOs, INGOs and Government sector about thyroid disorder for early diagnosis and to prevent from its complications.

KEYWORDS Awareness, Hypothyroidism, Hyperthyroidism, Thyroid Disorder, Nepal

1. Department of Internal Medicine, Devdaha Medical College and Research Centre, Bhaluhi, Nepal

2. Universal College of Nursing Sciences, UCMS, Bhairahawa, Nepal

3. Department of Neurology, Upendra Devkota National Institute of Neurological and Allied Sciences, Kathmandu, Nepal

4. Department of Nursing, Meditech International Nursing Institute, Butwal, Nepal

DOI: http//doi.org/10.3126/jucms.v7i2.27125

For Correspondence

Dr. Mahesh Raj Ghimire,

Department of Internal Medicine

Devdaha Medical College and Research Centre

Bhaluhi, Nepal

Email: ghimiremaheshraj@gmail.com 


\section{INTRODUCTION}

Thyroid disorder is important emerging disease in Nepal. With the advancement of laboratory equipment and investigation procedure even early stage thyroid disorder (subclinical hypothyroidism/hyperthyroidism) are detected in day to day clinical practice. Thyroid dysfunction is defined as the altered serum thyroid stimulation hormone (TSH) level with normal or altered thyroid hormones (free tri-iodothyronine- fT3 and free thyroxine- fT4).

Thyroid disorders and associated co-morbidities among females has been a burning issue globally at present and Nepal is not spare from it. Various studies show that females have inadequate knowledge of thyroid gland associated disorders and have many misconceptions regarding thyroid disorders. Many females are showing symptoms of the thyroid disorders but still they are unaware of the disease. ${ }^{2}$ So, extensive epidemiological studies are necessary to identify awareness about thyroid disorders in the community.

Aim of this study is to find awareness among adult females about thyroid disorder.

\section{MATERIAL AND METHODS}

This is a single-centered, descriptive and cross sectional study conducted among 105 subjects attending Neuro and Allied Clinic, Bhairahawa, Nepal from 15 August, 2019 to 20 August, 2019 (30/04/2076 to 04/05/2076 B.S.).

This study was conducted after receiving clearance from institutional review board from Upendra Devkota National Institute of Neurological and Allied Sciences, Verbal consent was taken after explaining about our research objectives and procedure and data were collected in semi structured questionnaire. Females from 18 to 50 years of age attending our Clinic were included who has had given consent for enrolment in our study. Since, our sampling technique is purposive, so we took 105 subjects.

Data processing was done by using computer Microsoft Excel 2010 and SPSS statistical software V20. Analysis was done by using descriptive statistics like frequency, percentage, standard deviation and mean. Inferential statistics (Chi square test) was used to show association between selected variables with confidence level $95 \%$.

\section{RESULTS}

A total of 105 subjects were included in this study. Age of respondents range from 21-40 years and majority 42 (40\%) were of 36-40 years age group, $42(40 \%)$ of subjects were housewife, $33(31 \%)$ were literate with cleared secondary level, $91(87 \%)$ were married as in Table 1.
Majority 93 (88\%) respondent responded females as most commonly thyroid disease occurring population, Six (9\%) had no idea and the rest responded for males with $33(31 \%)$ respondents had family members having thyroid disease and $17(16 \%)$ respondents had thyroid disease in (Table 2).

Among 17 respondents, cent percent were taking medicine as thyroid hormone in empty stomach in the morning followed by alternative treatment modalities as in Table 2 .

\section{Table 1. Baseline demography}

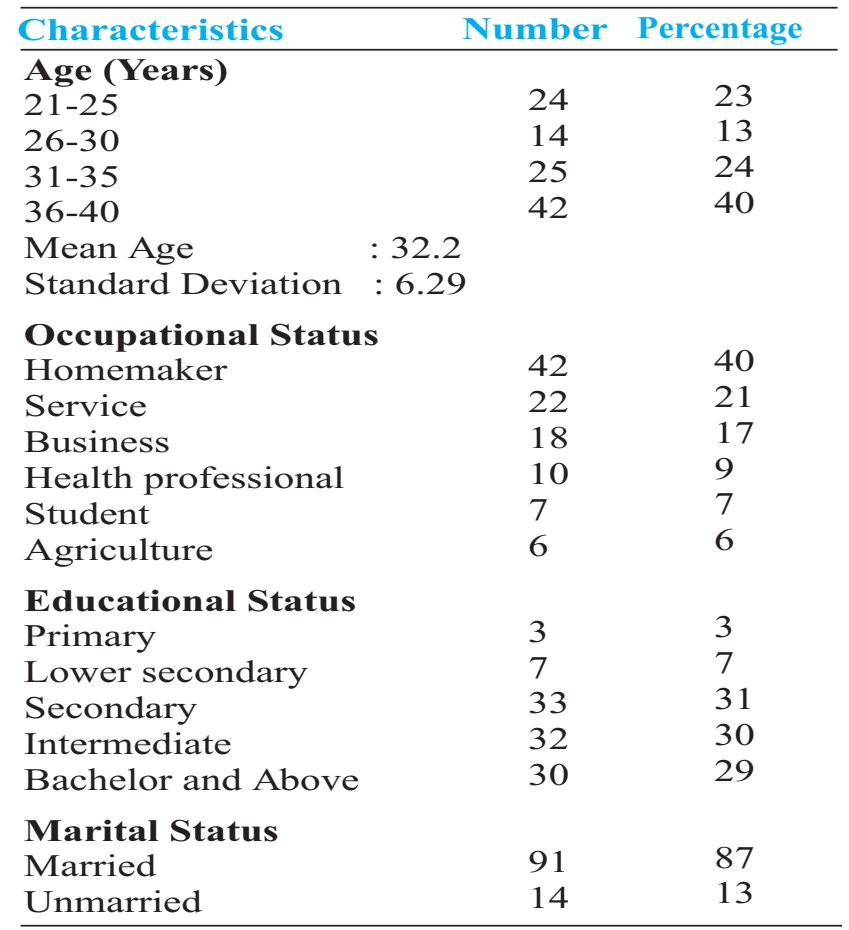

Table 2. Awareness regarding thyroid disease occurrence $(\mathrm{N}=\mathbf{1 0 5})$

\begin{tabular}{lll}
\hline Variables & Number & Percentage \\
\hline Most Commonly disease occurring population & 93 & 88 \\
Female & 3 & 3 \\
Male & 9 & 9 \\
Don't know & & \\
Family members having thyroid disease & 33 & 31 \\
Yes & 72 & 69 \\
No & & \\
Self Thyroid disease & 17 & 16 \\
Yes & 88 & 84 \\
No & & \\
Among yes, adopted treatment modalities (n=17)* & 17 & 100 \\
Intake of thyroid hormone & 6 & 36 \\
Alternative treatment modalities (Yoga, meditation, Exercise) & 6 & 27 \\
Thyroid operation & 5 & \\
Time of medicine intake (n=17) & & 100 \\
Before meal in the morning & 17 & \\
\hline
\end{tabular}




\section{Table 3. Awareness about thyroid disorder $(\mathbf{N}=105)$}

\begin{tabular}{|c|c|c|}
\hline Variables & Number & Percentage \\
\hline \multicolumn{3}{|l|}{ Heard about Thyroid Disorder } \\
\hline Yes & 105 & 100 \\
\hline \multicolumn{3}{|l|}{ Sources of information* } \\
\hline Television & 60 & 57 \\
\hline Friends & 59 & 56 \\
\hline Health professionals & 36 & 34 \\
\hline Radio & 33 & 31 \\
\hline \multicolumn{3}{|l|}{ Meaning of thyroid disorder* } \\
\hline Disease caused due to less thyroid hormone & 62 & 59 \\
\hline Disease caused due to excess thyroid hormone & 49 & 47 \\
\hline Presence of goitre & 25 & 24 \\
\hline Don't know & 22 & 21 \\
\hline \multicolumn{3}{|l|}{ Recognize signs and symptoms } \\
\hline Yes & 53 & 50 \\
\hline No & 52 & 50 \\
\hline \multicolumn{3}{|l|}{ Among yes, awareness on signs and symptoms of hypothyroidism $(\mathrm{n}=53)^{*}$} \\
\hline Weight gain & 49 & 91 \\
\hline Menstrual disorders & 38 & 71 \\
\hline Tiredness, Sleepiness & 35 & 66 \\
\hline Goitre & 30 & 57 \\
\hline \multicolumn{3}{|l|}{ Among yes, awareness on signs and symptoms of hyperthyroidism $(n=53)^{*}$} \\
\hline Weight loss & 39 & 74 \\
\hline Irritability and decreased sleep & 34 & 66 \\
\hline Diaphoresis & 33 & 63 \\
\hline Increased appetite & 30 & 57 \\
\hline \multicolumn{3}{|l|}{ Known about diagnostic test } \\
\hline Yes & 45 & 43 \\
\hline No & 60 & 57 \\
\hline \multicolumn{3}{|l|}{ Among yes, awareness on different test of thyroid disorders ( $\mathrm{n}=45$ ) } \\
\hline $\begin{array}{l}\text { Blood test } \\
\text { Plo }\end{array}$ & 23 & 51 \\
\hline T3 T4 TSH test & 22 & 49 \\
\hline \multicolumn{3}{|l|}{ Awareness on effects on health } \\
\hline Yes & 56 & 53 \\
\hline No & 49 & 47 \\
\hline \multicolumn{3}{|l|}{ Among yes, awareness about different health effects $(\mathrm{n}=56)^{*}$} \\
\hline Infertility & 45 & 81 \\
\hline Cardiovascular problems & 35 & 62 \\
\hline Thyroid cancer & 31 & 56 \\
\hline \multicolumn{3}{|l|}{ Awareness about pregnancy on Thyroid Disorders } \\
\hline Yes & 48 & 46 \\
\hline No & 57 & 54 \\
\hline \multicolumn{3}{|l|}{ Need of treatment of thyroid disorders } \\
\hline Yes & 95 & 90 \\
\hline No & 10 & 10 \\
\hline \multicolumn{3}{|l|}{ Treatment modalities of thyroid disorders * } \\
\hline No & 10 & 10 \\
\hline \multicolumn{3}{|l|}{ Treatment modalities of thyroid disorders * } \\
\hline Thyroid hormone should be taken & 64 & 61 \\
\hline Surgery for visible goitre & 24 & 23 \\
\hline Alternative remedies can cure thyroid disorders (Yoga, Meditation, Exercise) & 15 & 14 \\
\hline Don't know & 32 & 31 \\
\hline \multicolumn{3}{|l|}{ Once normal thyroid test after treatment } \\
\hline Continue medication with regular check-up & 33 & 31 \\
\hline Stop medication & 32 & 30 \\
\hline As per doctors suggestions & 22 & 21 \\
\hline Don't know & 18 & 17 \\
\hline
\end{tabular}

* Multiple responses (may exceed 100\%)
Cent percent i.e. 105 subjects were already heard about the disease condition before via television $60(57 \%)$, friends 59 $(56 \%)$, health professional $36(34 \%)$ and radio $33(31 \%)$ as in Table 3. Sixty two (59\%) subjects think that less thyroid hormone cause hypothyroidism and majority $53(50 \%)$ knew about the signs and symptoms of thyroid disorder; among them, for hypothyroidism weight loss $48(91 \%)$ is common symptoms followed by menstrual disorder 38 (71\%), tiredness, sleepiness $35(66 \%)$ and for hyperthyroidism, majority $38(74 \%)$ knew weight loss as a common symptom followed by irritability and decreased sleep 34 (66\%), diaphoresis $33(63 \%)$ as shown in Table 3.

Also, nearly half 45 (43\%) of the respondents knew about the diagnostic test of thyroid disorder; among them nearly half of the respondents $22(49 \%)$ answered blood test and other answered T3, T4, TSH test as diagnostic test of thyroid disorder shown in Table 3 .

Regarding thyroid screening test, 41 (39\%) respondents had undergone thyroid screening test. Among them, nearly half 18 $(44 \%)$ of the respondents were undergone thyroid screening test as per doctors suggestion.

Among 64 subjects who were not undergone thyroid screening test, 37 (58\%) did not knew about the test. Similarly, cent percent respondents answered storage of iodized salt in air tight container. Most 67 (64\%) respondents answered 'Yes' to the relation between iodine and thyroid disorder. Again, more than half of the respondents $56(53 \%)$ were aware about effects of thyroid disorders; among them eighth percent i.e., 45 respondents answered infertility as major effect on health followed by $35(62 \%)$ cardiovascular problems, $31(56 \%)$ thyroid cancer as shown in Table 3 .

Regarding pregnancy on thyroid disorders, nearly half 32 (46\%) respondents agreed about pregnancy on thyroid disorder. Among them most 21 (66\%) answered continuing of medication during pregnancy. Similarly, majority $95(90 \%)$ of respondents agreed need of treatment for thyroid disorder, among them, 64 (67\%) of respondents answered for mental and physical fitness as reason of treatment followed by for healthy and uncomplicated pregnancy $39(41 \%)$, prevention from heart disease $36(38 \%)$ and more than half $64(61 \%)$ of the respondents answered thyroid hormone should be taken for treatment of thyroid disorders and minority $15(14 \%)$ believed that alternative remedies can cure thyroid disorders (Yoga, Meditation, Exercise) whereas 33 (31\%) respondents had no idea about treatment modalities of thyroid disorders as shown in Table 3 .

Regarding once normal thyroid test after treatment, 33 (31\%) of respondents answered continue medication with regular check up while other $32(30 \%)$ answered medication can be 
stopped and minority $22(17 \%)$ had no idea about treatment monitoring. Our study shows most $60(57 \%)$ of respondents answered avoid cabbage, cauliflower and soya in the diet in thyroid disorder followed by weight maintenance for excessive weight gain $35(33 \%)$ and consumption of excess iodized salt in management $28(27 \%)$ where minority 25 (24\%) had no idea about the activities to be done by a thyroid disorder patient. More than half 37 (53\%) of the respondents had inadequate awareness on thyroid disorders whereas 33 $(47 \%)$ of the respondents had adequate awareness with mean score 19.9 with 12.4 standard deviation. The maximum score of awareness related question was 42 and minimum score was three obtained by the respondents out of total score 53 as in Table 4.

Table 4. Respondents awareness level about thyroid disorders

\begin{tabular}{|c|c|c|c|}
\hline \multicolumn{2}{|l|}{ Variables } & Number & Percentage \\
\hline \multicolumn{4}{|c|}{ Awareness level of respondents } \\
\hline Adequate awareness & & 33 & 47 \\
\hline Inadequate awarenes & & 37 & 53 \\
\hline Mean & 19.9 & & \\
\hline Standard Deviation & $: \quad 12.4$ & & \\
\hline Total Score & $: \quad 53$ & & \\
\hline Maximum Score & 42 & & \\
\hline Minimum Score & 3 & & \\
\hline
\end{tabular}

There is an association between age, education level, occupation status of respondents, respondent's family members having thyroid disease and self thyroid disease with awareness level ( $\mathrm{P} \square 0.005$ ). However, there is no association of marital status with awareness level as in Table 5.

Table 5. Association between level of Awareness with Selected Variables $(n=53)$

\begin{tabular}{|c|c|c|c|}
\hline Variables & $\begin{array}{l}\text { Adequate } \\
\text { awareness }\end{array}$ & $\begin{array}{l}\text { Inadequate } \\
\text { awareness }\end{array}$ & P value \\
\hline \multicolumn{4}{|l|}{ Age in years } \\
\hline $21-30$ & $16(49 \%)$ & $9(24 \%)$ & $0.035^{*}$ \\
\hline $31-40$ & $17(52 \%)$ & $28(76 \%)$ & \\
\hline \multicolumn{4}{|l|}{ Education level } \\
\hline Up to secondary level & $6(18 \%)$ & $23(62 \%)$ & $0.000 *$ \\
\hline Above secondary level & $27(82 \%)$ & $14(38 \%)$ & \\
\hline \multicolumn{4}{|l|}{ Occupational Status } \\
\hline Employed & $20(61 \%)$ & $13(35 \%)$ & $0.033 *$ \\
\hline Unemployed & $13(82 \%)$ & $24(65 \%)$ & \\
\hline \multicolumn{4}{|l|}{ Marital status } \\
\hline Married & $27(82 \%)$ & $35(95 \%)$ & 0.094 \\
\hline Unmarried & $6(75 \%)$ & $2(5 \%)$ & \\
\hline \multirow{2}{*}{\multicolumn{4}{|c|}{$\begin{array}{l}\text { Family members having thyroid disease } \\
\text { Yes }\end{array}$}} \\
\hline Yes & & & \\
\hline No & $15(46 \%)$ & $7(19 \%)$ & $0.017^{*}$ \\
\hline \multicolumn{4}{|l|}{ Self thyroid disease } \\
\hline Yes & $10(30 \%)$ & $1(93 \%)$ & \\
\hline No & $23(70 \%)$ & $36(97 \%)$ & $0.002 *$ \\
\hline
\end{tabular}

*P value- $\mathrm{Chi}^{2}$ test association

\section{DISCUSSION}

This descriptive research study was conducted to find out awareness regarding thyroid disorder among young adult females. In this study cent percent respondents had heard about thyroid disease. However, research on 250 females of Madhya Pradesh conducted on Assessment of Knowledge and Awareness regarding Thyroid Disorders in India showed most (70.8\%) females had heard about thyroid disease. ${ }^{3}$ This study was conducted to assess the awareness of 21-40 years age group females (mean age 32.2) which was supported by the study conducted to assess awareness and prevalence of hypothyroidism and hyperthyroidism in Bangladesh showed more than half $(51.03 \%)$ participants were in the age limit 21 40 years. ${ }^{4,5}$ Similarly a study conducted by Rehman H. et al (2015) showed mean age of participants 33.36. ${ }^{5}$ This findings are similar to the study conducted by Maharjan S and Chhetri HP, which showed majority $(87.3 \%)$ of participants were females. $^{2}$

This study showed nearly half (40\%) respondents were housewives and employed participants had adequate awareness compared to unemployed which was significant $(\mathrm{P}=0.000)$ which is supported by a study of Maharjan and Chhetri (2015) conducted to assess the knowledge, attitude and practice towards hypothyroidism among the patients attending at an Endocrine Clinic in Nepal showed more than half $(56 \%)$ of respondents were housewives suffered from the disease had low awareness level. ${ }^{2}$

In the present study intermediate and graduate participants had adequate awareness compared to primary, lower secondary and secondary level participants which was significant $(\mathrm{P}=0.003)$ which is supported by the study (Prasad et al, 2015) on health information seeking behaviour among hypothyroid patients in Chennai where graduate/post graduate participants had higher knowledge compared to those with lower or no formal education which was significant $(\mathrm{P}=0.013){ }^{6}$

In present study major source of information about thyroid disorders were television $(57 \%)$, friends $(56 \%)$ and health professional (34\%) which is supported by a study of (Prasad et al, 2015) where major health related information sources were friends (56\%) and healthcare professionals $(36 \%)^{6}$

In this study more than half (59\%) of respondents mentioned thyroid disorder means disease caused due to less thyroid hormone followed by disease caused due to excess thyroid hormone $(47 \%)$ and one fifth $(21 \%)$ had no idea about meaning of thyroid disorder similar to a research study of (Rai et al, 2016) that showed nearly half $(49.2 \%)$ correct response on meaning of thyroid disorder, $18.8 \%$ respondents gives incorrect responses whereas $26.4 \%$ had no idea about 
meaning of thyroid disorder. ${ }^{3}$ Similarly, a study conducted by Singh et al (2014) on knowledge, awareness and practice among patients with thyroid swelling attending Cytology Clinic in India showed half $(50 \%)$ of respondents knew correct meaning of hyper or hypothyroidism. ${ }^{7}$ Regarding types of thyroid disorder, this study indicated that most $(60 \%)$ respondents had no idea about types of thyroid disorder. However, a study conducted by (Rai et al, 2016) showed half $(50 \%)$ females had knowledge of terminologies associated with thyroid disorder.

This study indicated that almost one third (31\%) respondents have family members having thyroid disease which was supported by the study conducted by (Rafa, 2015) in which $(34.02 \%)$ had family history of thyroid disorders. ${ }^{4}$ One fifth $(16 \%)$ respondents were having thyroid disease and cent percent managed their hypothyroidism by oral thyroid hormone and correct on taking medication whereas thyroid operation (27\%) which was supported by a study of (Rai et al, 2016) which showed $(0.8 \%)$ had history of thyroid operation $(\mathrm{n}=250){ }^{3}$ Similarly a study of (Prasad et al, 2015) showed that cent percent participants managed their hypothyroidism by use of oral medication. ${ }^{6}$ However, a study of (Rafa, 2015) showed that three fourth (75\%) of participants were correct on taking thyroid medication. ${ }^{4}$

In this study half $(50 \%)$ of the respondents were able to recognize signs and symptoms of thyroid disorders which was supported by a study showed half of the participants were able to recognize signs and symptoms of hypothyroidism and hyperthyroidism (Singh et al, 2014). ${ }^{7}$ Similarly a study conducted by (Prasad et al, 2015) showed more than half $(53 \%)$ were able to recognize signs and symptoms. ${ }^{6}$ Majority answered weight gain (91\%) and three fourth answered weight loss $(74 \%)$ as a common signs and symptoms of hypothyroidism and hyperthyroidism respectively which was supported by the study showed $(50.4 \%)$ respondents answered weight gain/loss as common symptoms of thyroid disorders (Rai et al, 2016). ${ }^{3}$ Likewise, in a study of (Singh et al, 2014) majority $(79.5 \%)$ responded weight gain/weight loss as common sign and symptoms of hypothyroidism and hyperthyroidism respectively.?

This study indicated that almost one third (39\%) had undergone thyroid screening test mostly on suggestion of doctor and recognition of signs and symptoms (44\%) respectively whereas more than half $(61 \%)$ had not undergone thyroid screening test mostly due to lack of knowledge on thyroid test $(58 \%)$ which is supported by the study showed only $25 \%$ females had undergone the thyroid screening test mostly of them on suggestion of doctor (73\%) and about 55\% females had no idea about the thyroid screening test (Rai et al, 2016).
This study indicated that (14\%) respondents think that alternative remedies can cure thyroid disease which was supported by a study showed $(6 \%)$ of the participants had a belief in alternative medicine systems (Prasad et al, 2015) whereas a research study of (Rai et al, 2016) showed more than half (55.2\%) females thought that thyroid disorders could be cured by using alternative medicine.,

This study showed that most (31\%) females answered that thyroid medication should be continued if once thyroid test is normal, other (30\%) responded to stop and remaining (17\%) had no idea about it which was supported by a study showed $(35.20 \%)$ females responded that thyroid medication could be stopped once thyroid test report would be normal, other (35.6\%) have answered to continue medication and remaining $(29.20 \%)$ females have answered no idea about it (Rai et al, 2016). ${ }^{3}$ Similarly a study of Singh et al (2014) showed (40\%) of respondents thought that thyroid medication can be stopped once thyroid test are normal.

This study indicated that almost half $(46 \%)$ of respondents agreed about pregnancy on thyroid disorder. Among them most (66\%) answered continue medication during pregnancy whereas one third (34\%) answered stop medication during pregnancy which was supported by a study showed (34.80\%) females answered that thyroid medication could be taken during pregnancy, other (38\%) females responded to stop medication and remaining $(27.20 \%)$ answered don't know (Rai et al, 2016). ${ }^{3}$ Similarly a study conducted by (Singh et al, 2014) showed (37\%) had belief that thyroid medication should be stopped during pregnancy.

In this study most (57\%) of respondents perceived cabbage, cauliflower and soya should be avoided in the diet followed by weight maintenance for excessive weight gain (33\%), consume excess iodized salt (29\%) whereas a research study of (Rai et al, 2016) showed nearly half (44.8\%) agreed on avoidance of cabbage, cauliflower and soya in the diet, use of excessive iodized salt to treat thyroid deficiency (46.8\%) and more than half $(54.4 \%)$ responded weight reduction for excessive weight gain. ${ }^{3}$

This study indicates that less than half $(47 \%)$ respondents had adequate awareness regarding thyroid disorders while (53\%) of the respondents had inadequate awareness with the mean score of awareness 19.9. Likewise a study of Rai et al, 2016 showed that females had inadequate knowledge of thyroid gland and associated disorders and they had myths and misconception regarding thyroid disorders. ${ }^{3}$

The limitation of the study is single centred, clinic based and sample is less.

\section{CONCLUSION}


This research study concludes that awareness regarding thyroid disorders is not even fifty percent. So, it is mandatory to perform public awareness program by NGOs, INGOs and government sector about thyroid disorder for early diagnosis, screening test and to prevent from its complications.

\section{ACKNOWLEDGEMENTS}

Mr. Amar Khadka, Neuro and Allied clinic, Bhairahawa.

Mrs Rasmi Kandu, Neuro and Allied Clinic, Bhairahawa

Mr. Asin Gurung, Neuro and Allied Clinic, Bhairahawa.

Dr. Rachana Nakarmi, Upendra Devkota Memorial National Institute of Neurological and Allied Sciences, Kathmandu.

\section{REFERENCES}

1. Nikiforov YE, Biddinger PW, Thompson LD. Diagnostic pathology and molecular genetics of the thyroid: a comprehensive guide for practicing thyroid pathology: Lippincott Williams \& Wilkins; 2012.

2. Maharjan S, Chhetri HP. Assessment of interventions by pharmacist in improving knowledge, attitude and practice towards hypothyroidism among the patients attending at an endocrine clinic in Nepal. Indian Journal of Pharmacy Practice. 2015;8(2):67.

3. Rai S, Sirohi S, Khatri A, Dixit S, Saroshe S. Assessment of knowledge and awareness regarding thyroid disorders among women of a cosmopolitan city of central India. Ntl J Community Med. 2016;7(3):219-22.

4. Rafa MR. Awareness and Prevalence of Hyperthyroidism and Hypothyroidism in Endocrine Disordered patients of Bangladesh: East West University; 2016.

5. Rehman H, Rehan SJ, Ishaq H, Shakeel S, Hashmi F, Naveed S. Hypothyroidism question towards quality and patient centricity. Open Journal of Endocrine and Metabolic Diseases. $2015 ; 5(02): 19$.

6. Perumal S, Prasad S, Surapaneni K, Joshi A. Health informationseeking behavior among hypothyroid patients at Saveetha Medical College and Hospital. Ethiopian Journal of Health Sciences. 2015;25(2):147-54.

7. Singh A, Sachan B, Malik N, Sharma V, Verma N, Singh C. Knowledge, Awareness, and Practices Among Patients with Thyroid Swelling Attending Cytology Clinic in a Medica College, Meerut. IJCP Group of Publications. 2014;24(8):753. 